\title{
The Optimization Method on the Compound Ecosystem of Digital City Planning
}

\author{
Hu Xiangdong ${ }^{1}$, Liu Mingguo ${ }^{2}$, and Yang Siliang, ${ }^{3, *}$ \\ ${ }^{1}$ Protection and Renovation Office of Xi'an Qujiang Daming Palace Ruins Area, Xi'an, 710016, China; ${ }^{2}$ Small Town \\ Center of Shanxi Province, Taiyuan, 030013, China; ${ }^{3}$ School of Architecture, Chang'an University, Xi'an, 710061, \\ China
}

\begin{abstract}
The information society and digital city provides background for the research and practice of digital urban planning, with the further research and development of digital city, the traditional urban planning must gradually developed into a digital urban planning. This paper first discusses the basic concept of digital urban planning, and then determine the technology system of digital urban planning, and discusses the digital urban planning information content; then, obtaining, from digital urban planning information processing and information expression in three aspects, discusses the digital urban planning many technical methods; finally, discusses the way of comprehensive application of various technology and methods, and looks forward to the development prospect of digital urban planning and technical method. With the characteristics of various technical methods of digital city planning, and it is replaced, some can therefore, this paper argues that: in the research and practice of digital city planning, it is necessary in the comprehensive considering the comprehensive application of plan formulation technology method based technical factors and other factors, so that the various technical methods can complement each other, develop the integrated benefit.
\end{abstract}

Keywords: Digital city planning method, information acquisition, information processing, variational method.

\section{INTRODUCTION}

In urban areas, an important sign of the construction of digital city can be regarded as the city entered or are preparing to enter the information society. Digital city comprehensive use of $3 \mathrm{~S}$ technology, network technology, virtual reality technology and other technology, have on urban geography, environment, resources, society, economy, population and other complex system digital, network, virtual simulation, visualization and decision support and other powerful [1]. Digital city can be regarded as the real city (city of matter and its social and political economic characteristics of complex virtual control). Digital city not only can provide convenience for people's daily life and production, but also can help people better understand the city and construction of city, in order to realize the sustainable development of the city $[2,3]$.

In the field of city, an important sign of the construction of digital city can be seen as the city entered or are preparing to enter the information society [4]. Digital city comprehensive use of $3 \mathrm{~S}$ technology, network technology, virtual reality technology and other technology, has the city geography, environment, resources, society, economy, population and other complex system of digital, networked, virtual simulation, visualization and decision support and other powerful. Digital city can be regarded as the real city (city of matter and its social and political economic characteristics of complex virtual control). Digital city not only can provide convenience for people's daily life and production, but also can help people better understand the city and construction of city, in order to realize the sustainable development of the city [5-8].

This paper firstly put forward the city planning to the new idea to optimize city compound ecological system at home and abroad, and the initial establishment of the city planning theory system of city compound ecological system optimization function. This paper describes the modern western city planning theory on the evolution of history, to optimize city system can be seen, along with the evolution of city planning thoughts city planning, optimization function of city system and constantly improve; discusses the factors mutual influence of city planning and city complex ecological system and natural system mechanism; respectively from city white city economic system city social system three aspects of optimization function of city compound ecological system of city planning. In this paper, in order to effectively establish contact information technology and city planning, the thesis introduced the digital city planning information content. The process of city planning is the process of information flow, therefore, research more combined with the feature of information content in the city planning and the flow of information to carry out technical method will be conducive to the technical method research combined with the whole process of city planning together. 


\section{THE RAPID PROCESS OF CITY WITH COMPLEX PROBLEM}

\subsection{The Concept of Digital City Planning}

Social information at the same time, China is still faced with the problem of Rapid City, a large number of rural population into the city, city population and land use scale is continually expanding, city infrastructure construction is facing severe challenges. The end of 2002 China's total population reached 1285000000 people, among them, the non - agricultural population of 349340000 people, accounting for $27.9 \%$ [9]. Plus in recent years a large number of agricultural population into the city, if to live and work in the city's population reflects the proportion of city level, city level actually in China are far higher than non agriculture population proportion, relevant data show: the end of 2001 the city of our country urbanization level has reached $37.7 \%$ [10]. The $\mathrm{S}$ curve of city development was shown in Fig. (1).

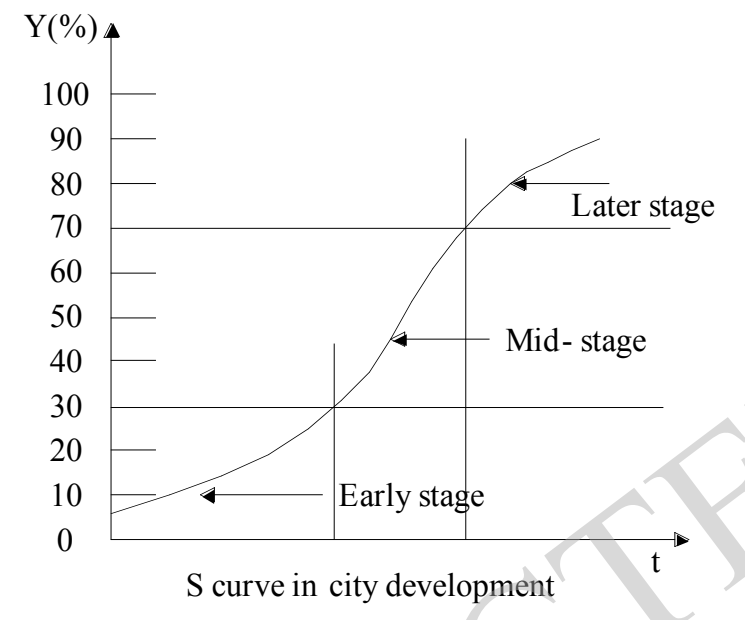

Fig. (1). The S curve of city development.

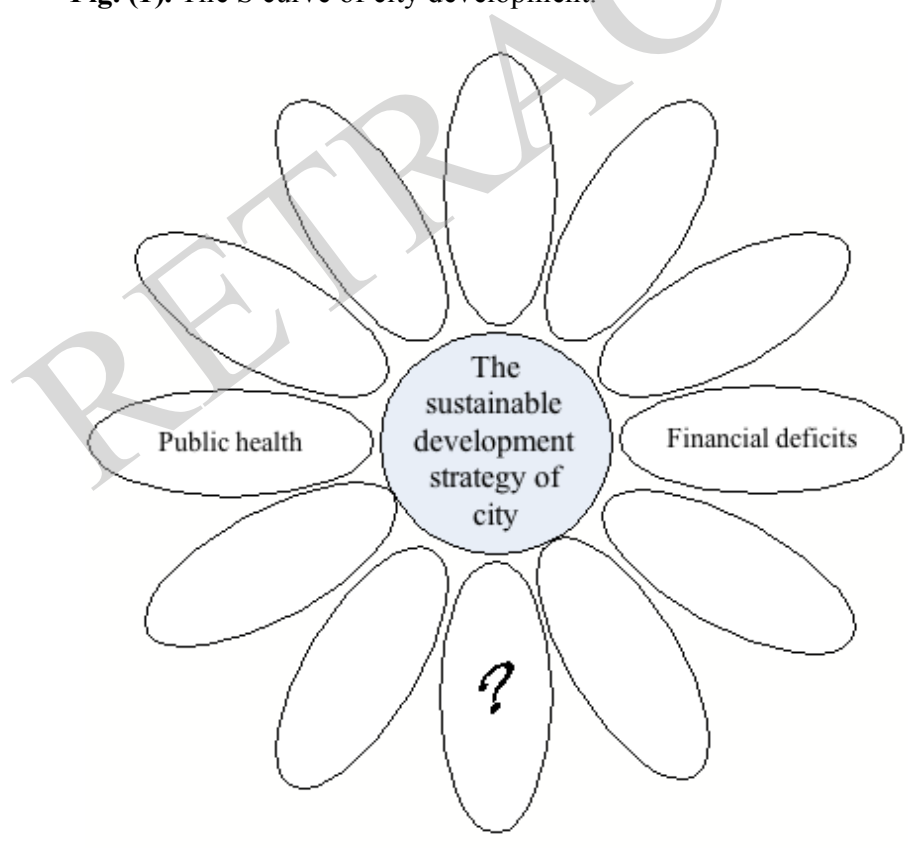

Fig. (2). The sustainable development strategy of city.

\subsection{Present Situation of Research on the Process of Digi- tal City}

The modern urban planning theory is based on three sources: idealism, modernism and humanism. The core of idealism is the understanding of the contradiction of the artificial environment and natural environment is more and more thorough, advocated the combination of city and countryside. Ideal construction of ecological city goal in twentieth Century after 80 years and gradually developed into the world widely accepted sustainable development strategy (see Fig. 2).

Whether the planning theory or methods of planning development, all put forward the urgent request to the technical method, in the city planning in the application of advanced technology to improve the content of city planning. Only the effective use of all kinds of advanced technology and methods, to ensure the planning method is advanced from the idea into reality, also can guarantee the planning ideology of science is reflected in the practice of urban planning [11].

\section{CITY PLANNING THEORY AND METHOD}

\subsection{Review of the Existing Digital City Planning Content}

City complex ecological system mainly consists of three subsystems. The process of research and development, we must first carry out the overall system architecture design, this is the requirements of software engineering. In order to achieve the city modeling requirements, the author designed the overall system architecture was shown in Fig. (3).

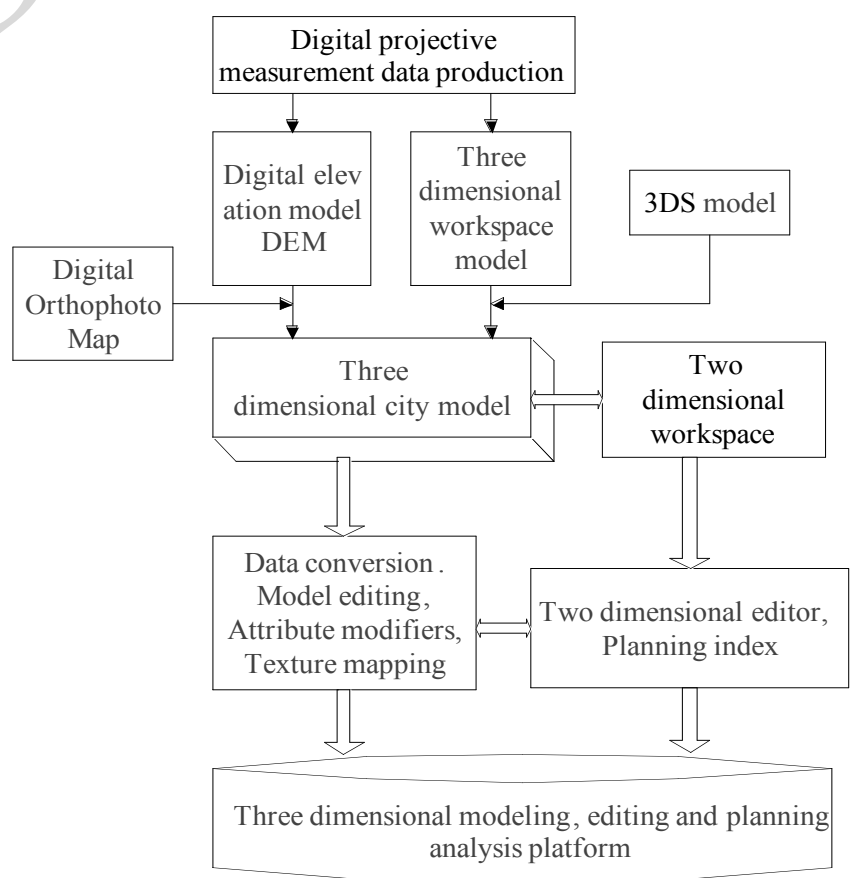

Fig. (3). The designed the overall system architecture.

The structure of the two aspects of social economics subsystem includes biological structure and population. The former can be divided into age structure and sex structure; the latter can be classified as urban and rural population constitutes three aspects from the angle of economics, the labour structure and occupational structure, and from the angle of 
sociology can divide constitute the population quality, population structure of income and the population structure of consumption in three ways.

The city can be divided into several subsystems, each subsystem and contains many subsystems, if the city every subsystems, each level, each association as city of onedimensional case, city system is a huge system of $\mathrm{N}$ dimension, and the city ecological system. Generally the main and the natural ecological system of relative to character, is a subsystem of city system, the author thinks that in its semantic mainly tend to natural dimension, city of compound ecological system is including the natural dimension, economic and social dimensions, the connotation is bigger than the city ecological system significantly.

\subsection{Construction of the Evaluation Index System}

According to the actual need of decision-making evaluation, the evaluation grade standard divided into good, good, general, poor, poor in five levels, namely the comments set for:

$V=\left\{v_{1}, v_{2}, v_{3}, v_{4}, v_{5}\right\}=\{$ good, better, common, worse, poor $\}$

The introduction of AHP and expert scoring method, the two two important properties of relatively, the judgment matrix is established, the index weights of each layer matrix characteristic values, A was defined as the important degree of the fuzzy subsets of $U$, then the criterion layer B indexes on the weight of target layer A set

$A=\left\{a_{1}, a_{2}, a_{3}\right\}$, in which $\sum_{i=1}^{3} a_{i}=1$

The index of the corresponding element layer $\mathrm{C}$ criterion layer B weight set

$A_{i}=\left\{a_{11}, a_{12}, a_{13}, a_{14}\right\},(\mathrm{i}=1,2,3)$

In it: $\sum_{j=1}^{4} a_{i j}=1$

Index weight of each index in the D elements corresponding to the layer of $\mathrm{C}$ set

$A_{i j}=\left\{a_{i j 1}, a_{i j 2}, a_{i j 3}\right\}$

The selected field $\mathrm{M}$ city planning experts and $\mathrm{N}$ city residents $(\mathrm{N}=2 \mathrm{M})$ consisting of a panel of judges, in an index, suppose $\mathrm{M}$ experts have the name of the $\mathrm{M}$ and $\mathrm{N}$ city residents have $n$ that 'good' the assessment value of $\mathrm{A}$. for example, the 20 experts assume that the selected in 30 of 12 individuals and 40 residents in the city that the degree of satisfaction with the consent of the open space environment evaluation grade.

The evaluation of single factor decision matrix set:

$$
R_{i j}=\left\{\begin{array}{l}
r_{i j 11}, r_{i j 12}, r_{i j 13}, r_{i j 14}, r_{i j 15} \\
r_{i j 21}, r_{i j 22}, r_{i j 23}, r_{i j 24}, r_{i j 25} \\
r_{i j 31}, r_{i j 32}, r_{i j 33}, r_{i j 34}, r_{i j 35}
\end{array}\right\}
$$

$$
B_{i j}=A_{i j} \cdot R_{i j}=\left\{a_{i j 1}, a_{i j 2}, a_{i j 3}\right\} \cdot\left\{\begin{array}{l}
r_{i j 11}, r_{i j 12}, r_{i j 13}, r_{i j 14}, r_{i j 15} \\
r_{i j 21}, r_{i j 22}, r_{i j 23}, r_{i j 24}, r_{i j 25} \\
r_{i j 31}, r_{i j 32}, r_{i j 33}, r_{i j 34}, r_{i j 35}
\end{array}\right\}
$$

$B=\left[\begin{array}{lll}a_{x} & b_{x} & d_{x} \\ a_{y} & b_{y} & d_{y} \\ a_{z} & b_{z} & d_{z}\end{array}\right]$

\subsection{Conceptual model of Digital City}

How to influence the city planning to produce, test platform is bound to city complex ecosystem. Through the comparative analysis of city compound ecological system before and after effect of city planning, we can test the optimization function of city planning, city planning to further improved and adjusted through inspection feedback. Therefore, city complex ecosystem is the inspection table effect of city planning (Fig. 4).

Conceptual model of digital city, digital city is the description of generality, it reflects the relationship between the digital city technologies, the content of information infrastructure and other elements in a certain extent, although the digital city technologies, information content and infrastructure in this article will combine the contents of digital city planning technology system information content, technical methods, respectively, to elaborate, but here the concept model of digital city of the overall interpretation is needed.

\subsection{Basic Information of City Spatial}

For city planning, spatial resolution of city spatial basic information is a very important index, spatial resolution correspond to different scale, and city planning at different stages of the planning results required precisely correspond to different scale, such as total gauge results and detailed results scales far. At the same time, city spatial basic information in different scales can be covered city geographical range usually is also not the same, between city spatial basic information of spatial resolution, scale and can cover the city geographical scope of the three corresponding relationship is shown in Table $\mathbf{1 .}$

Digital city thematic information refers to urban spatial basic information on the performance of urban sectors of information relates to all aspects of the city. Such as urban public infrastructure (water, electricity, heat, gas), cadastral, traffic, communication, land use, planning, resource, environment, geology, water conservancy, disaster, emergency, tourism, public security, civil air defense, finance, taxation, trade, business, culture and education, agriculture etc.. The scope of urban thematic information covers is closely related with the urban planning is very extensive, involving almost the entire city trades, departments and units, wherein the relationship with planning management information, real estate information, land information, environmental information, integrated network information, traffic information, economic development information, demographic information, cadastral information etc. and urban planning is most closely. 


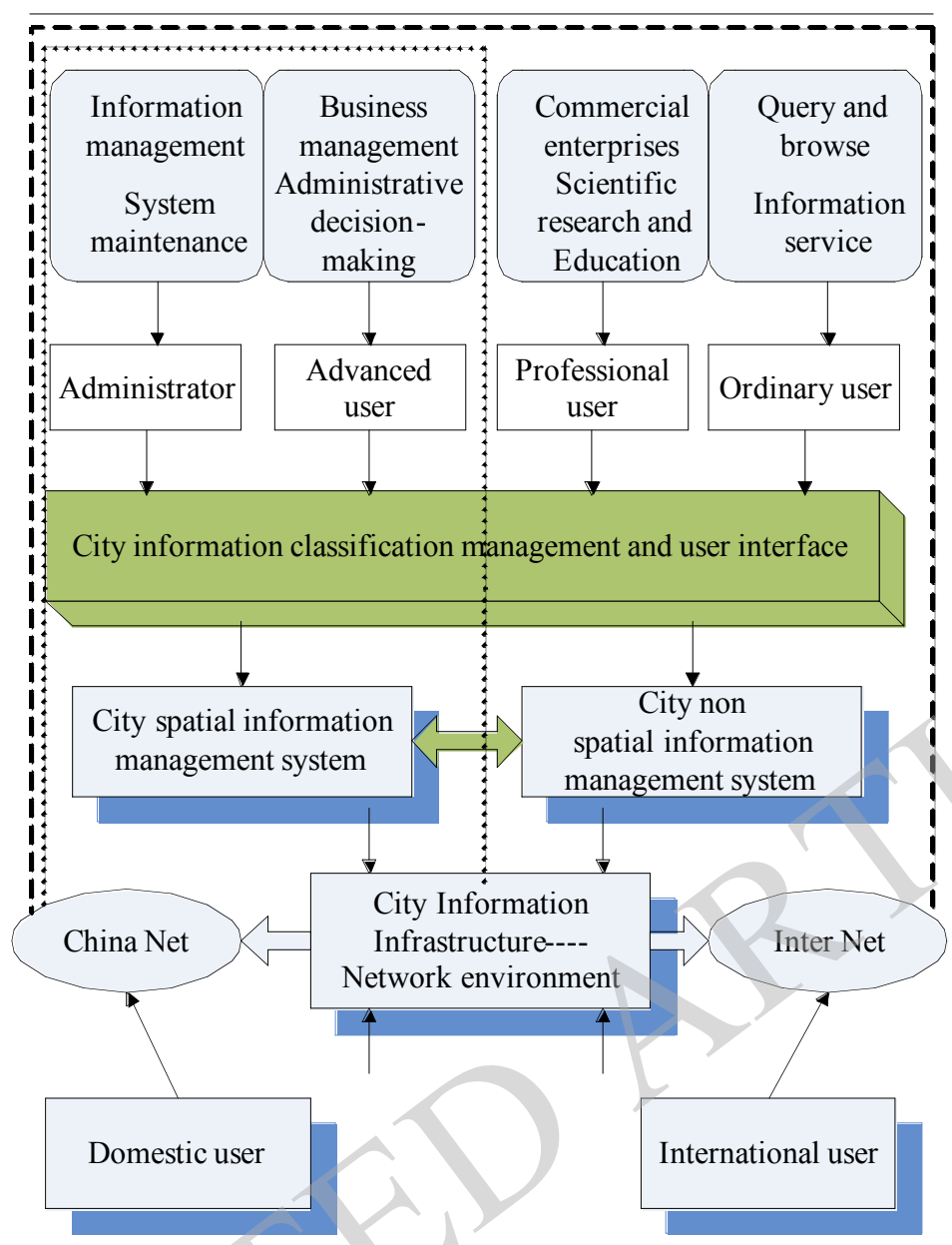

Fig. (4). City complex ecosystem.

Table 1. Space information scale and the geographical scope of city corresponding to different spatial resolution.

\begin{tabular}{|c|c|c|c|c|c|c|c|}
\hline \multirow{3}{*}{$\begin{array}{l}\text { Geographical } \\
\text { Scope of City }\end{array}$} & \multirow{3}{*}{ Scale } & \multicolumn{2}{|c|}{ DLG } & \multicolumn{2}{|c|}{ DOM } & \multicolumn{2}{|c|}{ DEM } \\
\hline & & Scale & \multirow{2}{*}{ Spatial Resolution } & \multirow{2}{*}{ Scale } & Scale & \multirow{2}{*}{ Scale } & Scale \\
\hline & & (m) & & & (m) & & (m) \\
\hline \multirow{2}{*}{ Built up area } & $1: 500$ & 0.1 & \multirow{6}{*}{$\begin{array}{c}\text { Road edge, } \\
\text { Municipal facili- } \\
\text { ties, Place names, } \\
\text { Control point, etc }\end{array}$} & $1: 1000$ & 0.2 & \multirow{2}{*}{$1: 2000$} & \multirow{2}{*}{$2 \times 2$} \\
\hline & $1: 1000$ & 0.2 & & $1: 2000$ & 0.4 & & \\
\hline \multirow{2}{*}{ Urban planning } & $1: 1000$ & 0.2 & & $1: 2000$ & 0.2 & $1: 2000$ & $2 \times 2$ \\
\hline & $1: 2000$ & 0.4 & & $1 ; 5000$ & 0.5 & $1: 10000$ & $10 \times 10$ \\
\hline \multirow{2}{*}{ Other districts } & $1: 5000$ & 1.0 & & $1: 5000$ & 0.5 & \multirow{2}{*}{$1: 10000$} & \multirow{2}{*}{$10 \times 10$} \\
\hline & $1: 10000$ & 2.0 & & $1: 10000$ & 1.0 & & \\
\hline
\end{tabular}

In Table 1 on the basis of, can use the expansion of city construction speed and area was shown in Fig. (5) is obtained.

\section{RESULTS AND DISCUSSION}

\subsection{Construction and Implementation}

Control the contents of the first detailed planning, establishment is the control system, control system is the main factor affecting the control rules of control function. Any city construction activities, whether it is the comprehensive development or the individual construction, its interior components including land use, environmental capacity, building construction, city design guide, six facilities and activities. These six aspects basic overview of all aspects of city construction, so the regulatory detailed planning is through the control and guidance for city construction and development of the above six aspects. 

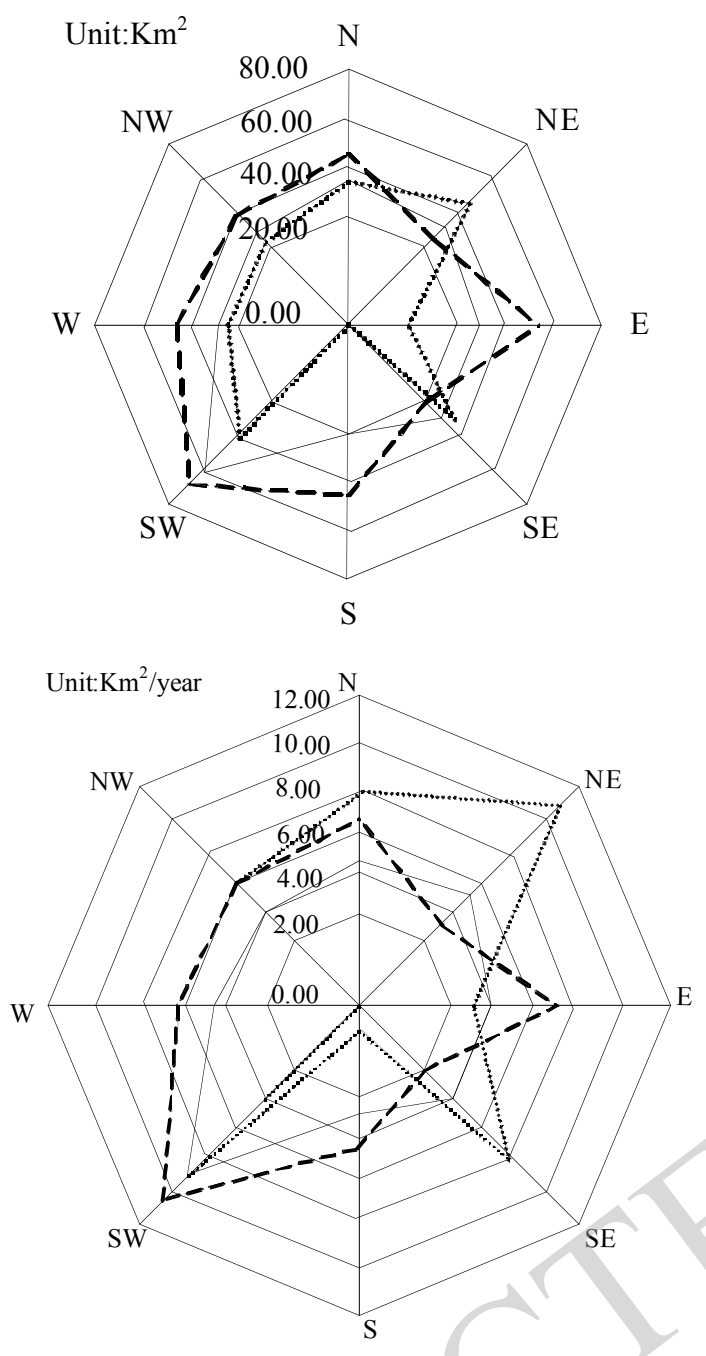

Fig. (5). The expansion of city construction speed and area.

Spatial decision is a decision in order to achieve some goal or goal set, according to certain constraints, in choosing candidate scheme for multiple spatial behavior in the complex process. The decision process of spatial behavior, cognitive style of people can be shown in Fig. (6). In Fig. (6), the existing experience, constraint condition and psychological factors limiting belong to descriptive knowledge, mathematical and statistical models existing belongs to procedural knowledge. In the digital city planning, descriptive knowl-

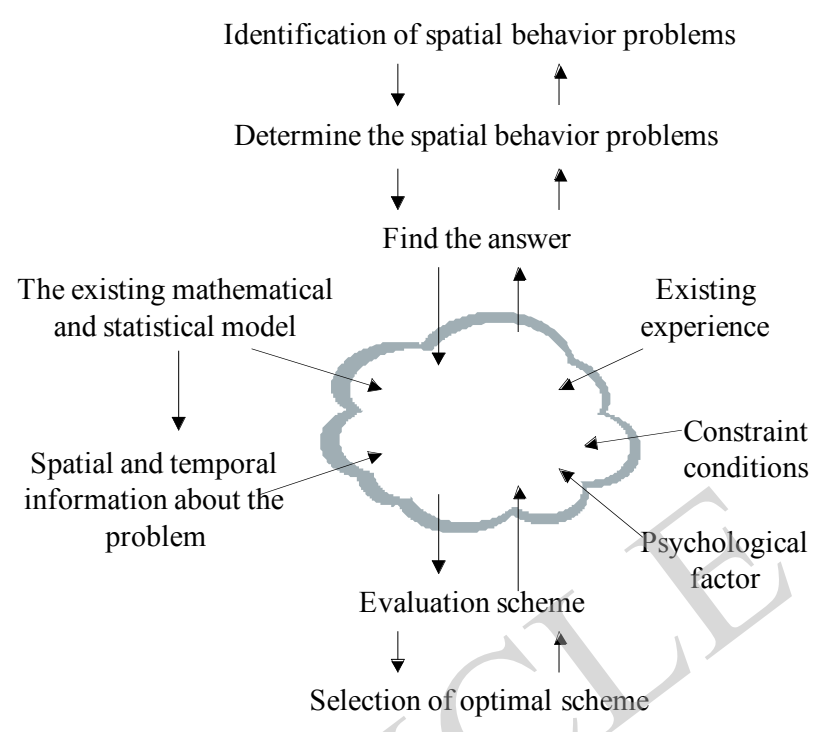

Fig. (6). The decision process of spatial behavior.

edge and procedural knowledge is organized according to the operating mechanism of logical reasoning mode field of city planning specialty knowledge, form the space behavior decision model of digital city planning.

\subsection{Information Acquisition of City Planning}

The membership degree and weight generation model of fuzzy comprehensive evaluation, calculate the measure of optimization function effects on city complex eco system after the implementation of city planning, which ranges from $0-1$, the effect of optimization function is divided into five levels:

1) $0.9 \leq v_{j} \leq 1.0$; optimization function is good

2) $0.8 \leq \mathcal{V}_{j} \leq 0.9$; optimization function is better

3) $0.7 \leq v_{j} \leq 0.8$; optimization function is common

4) $0.6 \leq v_{j} \leq 0.7$; optimization function is poor

5) $0 \leq v_{j} \leq 0.6$; optimization function is worse

This paper believes that the urban compound ecosystem optimization program overall urban planning based on the

Table 2. Detailed planning control system.

\begin{tabular}{|c|c|}
\hline Control System & Control Factors \\
\hline \hline Land use & Land area, Land boundary, Land property, Land use compatibility \\
\hline Environmental capacity & Floor area ratio, Building density, Density of registered inhabitants, Green rate \\
\hline Building construction & Building height limit, Setback, Building interval \\
\hline City Design Guide & Building mass, Architectural form, Architectural color, Building enclosed space, Building sketch \\
\hline Supporting facilities & Municipal facilities, Communal facilities(administration, commercial, culture and education, sports and health \\
\hline Activities & Traffic activities, Environmental protection regulations \\
\hline
\end{tabular}


Table 3. Scheme evaluation of stage city overall planning.

\begin{tabular}{|c|c|}
\hline Evaluation Level & Evaluation Index \\
\hline \hline Properties and functions of city & $\begin{array}{c}\text { Whether city property prominent personality; } \\
\text { Whether city function orientation accurate; }\end{array}$ \\
\hline Population and land use scale of city & $\begin{array}{c}\text { Whether city land scale is proper; } \\
\text { Whether city population scale is reasonable; }\end{array}$ \\
\hline City development direction & $\begin{array}{r}\text { Whether it is conducive to the adjustment of the city structure, optimize the layout form; } \\
\text { Whether it is conducive to the city function organization, improve operation efficiency; } \\
\text { Whether development center is in the direction of economic; }\end{array}$ \\
\hline City spatial structure & $\begin{array}{r}\text { Whether the city spatial structure is in accordance with the development stage of the city; } \\
\text { City center function as commercial, service etc, industrial function, and live }\end{array}$ \\
\hline
\end{tabular}

evaluation target, should be carried out according to Table $\mathbf{3}$ evaluation level and evaluation index:

City Planning in the implementation of a certain number of years (including all levels after the superposition of planning), in the city during the development of complex ecological system optimization what city play what function. To this effect, directly influence and determine the position and the role of city planning in the society, also determines the social awareness of planning. Performance evaluation through the implementation of the plan can not only comprehensive analysis of the effect of the implementation of effective planning, monitoring, supervision and the planned results and practical condition of compliance, and based on which the relevant information feedback mechanism, can for the next round of planning and related policy formulation and implementation of planning management system presented in the form of correction, adjustment of the proposal, make the city planning system into a benign cycle.

\section{CONCLUSION}

Through the above work, this thesis hope technology method of digital city planning to make a comprehensive study, in fact, this thesis can do is very limited, with the solution of some problems, the emergence of more problems, there are some problems at the beginning of writing this thesis is going to answer but is still questioned. Of course, put forward the problem itself is also very important for the further research.

\section{CONFLICT OF INTEREST}

The authors confirm that this article content has no conflict of interest.

\section{ACKNOWLEDGEMENTS}

The work is supported by Shaanxi Province Social Science Funds Projects (2014D39) and by 2014 science and Technology Project Plan of Housing and Urban-Rural Development-Soft Science Research Project (Project No. 2014R2-026).

\section{REFERENCES}

[1] T. Beatley, and M. Bekoff, "City Planning and Animals: Expanding Our Urban Compassion Footprint," Ethics, Design and Planning of the Built Environment, Springer Netherlands, pp. 185-195, 2013.

[2] L. Rudin, P. Lions, and S. Osher, "Multiplicative denoising and deblurring: theory and algorithms," in Osher S and Paragios N, Editors, Geometric Level Set Methods in Imaging, Vision and Graphics, Springer, pp. 103-119, 2003.

[3] L. Denis, F. Tupin, J. Darbon, and M. Sigelle, "SAR Image Regularization with Fast Approximate Discrete Minimization," IEEE Trans Image Process., vol. 18, no. 7, pp. 1588-600, 2009.

[4] J. Shi, and S. Osher, "A Nonlinear Inverse Scale Space Method for a Convex Multiplicative Noise Model," SIAM J. Imaging Sciences, vol. 1, no. 3, pp. 294-321, 2008.

[5] Y. Huang, L. Moisan, M.K. Ng, and T. Zeng, "Multiplicative Noise Removal via a Learned Dictionary," Image Processing, IEEE Transactions on, vol. 21, no. 11, pp. 4534- 4543, 2012.

[6] D. Chen, and L. Cheng, "Spatially Adapted Total Variation Model to Remove Multiplicative Noise," Image Processing, IEEE Transactions on, vol. 21, no. 4, pp. 1650-1662, 2012.

[7] A. Dang, H. Shi, and Q. Mao, "GIS and RS Application Study on Urban Dynamic Development," Geographic Information Sciences, vol. 8, no. 2, pp. 122 128, 2002.

[8] C. R. Council, "Review of capital city strategic planning systems," COAG Reform Council, Sydney, 2012.

[9] Fuzzy planning, "The role of actors in a fuzzy governance environment," Ashgate Publishing, Ltd., 2012.

[10] S. Larson, "Building Like Moses with Jacobs in Mind": Contemporary Planning in New York City,” Temple University Press, 2013.

[11] Whose public space?, "International case studies in urban design and development," Routledge, 2013.

Received: June 10, 2015

(C) Xiangdong et al.; Licensee Bentham Open.

This is an open access article licensed under the terms of the (https://creativecommons.org/licenses/by/4.0/legalcode), which permits unrestricted, noncommercial use, distribution and reproduction in any medium, provided the work is properly cited. 